\title{
Prevalence of kairomone-induced diapause in Daphnia magna from habitats with and without fish
}

\author{
Miroslaw Slusarczyk • Agnieszka Ochocka • \\ Przemysław Biecek
}

Received: 30 March 2012/ Accepted: 18 May 2013/Published online: 31 May 2013

(C) The Author(s) 2013. This article is published with open access at Springerlink.com

\begin{abstract}
The prevalence of the diapause response of the freshwater crustacean Daphnia magna to chemical cues on fish predation was evaluated in 35 clones originating from 14 European water bodiesinhabited or not inhabited by fish. Clonal lineages of experimental animals were cultured for 4 weeks in the presence or absence of water to which an extract of faeces of crucian carps (Carassius carassius), that were fed with Daphnia, was added. The proportion of females producing diapausing forms during the experimental period was used as a measure of the diapause response. A positive diapause response to fish predation cues was observed in $43 \%$ of investigated clones that originated from $71 \%$ of the water bodies tested. This indicated that the diapause response to fish scent is a common phenomenon in Daphnia magna from
\end{abstract}

Guest editors: Marina Manca \& Piet Spaak / Cladocera: Proceedings of the 9th International Symposium on Cladocera

M. Slusarczyk $(\bowtie)$

Department of Hydrobiology, Biological and Chemical Research Centre, University of Warsaw, Żwirki i Wigury 101, 02-089 Warszawa, Poland

e-mail: m.slusarczyk@uw.edu.pl

\section{A. Ochocka}

Institute of Environmental Protection-National Research Institute, Krucza 5/11d, 00-548 Warszawa, Poland

P. Biecek

Institute of Applied Mathematics, University of Warsaw, Banacha 2, 02-097 Warszawa, Poland various locations in Europe. Surprisingly, no signs of a stronger diapause reaction to the tested cues were found in Daphnia originating from water bodies inhabited by fish compared with those from fish-free habitats.

Keywords Predator avoidance $\cdot$ Inducible defences · Predation · Fish cues $\cdot$ Chemical communication

\section{Introduction}

Diapausing stages that offer protection against unfavourable environmental conditions may be used by organisms to survive periods of abiotic or biotic stress, including temporal intensification of predatory pressure. The formation of protective diapausing stages prior to or at the time of intensified predatory pressure might enhance the chances of their persistence if the dormant stages are more resistant to consumption than the active forms, like they are in copepods (Hairston \& Olds, 1984; Marcus, 1984) or cladocerans (Mellors, 1975). It might also increase these chances when the dormant stages are deposited in places not accessible to both active animals and their key predators, such as in anoxic lake sediments, where large quantities of resting forms of various aquatic organisms may wait for favourable periods (Brendonck \& De Meester, 2003; Gyllström \& Hansson, 2004).

Like many other seasonal phenomena, the annual intensification of predatory pressure may be anticipated 
by potential prey by the detection of token seasonrelated cues correlated with the selective force (e.g. photoperiod). Evidence of this seasonal phenomenon is scarce and is limited to one calanoid species Eudiaptomus sanguineus in two water habitats merely (Hairston, 1987). Some other studies have revealed that chemical cues associated with fish predation on planktonic crustaceans of the genus Daphnia may induce diapausing egg formation by conspecific females (Pijanowska \& Stolpe, 1996). This response was explained as an inducible protective mechanism against unpredictable intensification of predatory pressure. So far, the few described examples of diapause induction by fish kairomones in Daphnia are limited to specimens originating from a single site: the shallow coastal lake Grosser Binnensee located in northern Germany, which is inhabited by fish. A positive diapause response to fish kairomones was observed in three species of Daphnia (D. magna, D. pulicaria and $D$. longispina) isolated from this lake (Slusarczyk et al., 2012). The most intense diapause response to fish kairomones was found in D. magna, the largest of the three tested species. Due to its relatively large body size and high visibility, D. magna experiences the strongest predation pressure from positive size-selective fish under natural conditions. Outside the aquatic environment, we are aware of only a single example of a possible diapause response evoked by predator-released compounds in a terrestrial species: kairomones of the predacious mite Typhlodromus pyri are claimed to induce diapause in the herbivorous twospotted spider mite Tetranychus urticae (Kroon et al., 2008). It is interesting whether the current dearth of evidence for kairomone-induced diapause is due to its incidental occurrence, or because this field has not been the subject of much investigation.

The aim of this study was to investigate the prevalence of kairomone-induced diapause in the crustacean D. magna (best known for its diapause response to fish kairomones) originating from various European water bodies. We examined the frequency of this phenomenon in animals from lakes and ponds with and without fish. Since costly adaptations may get lost where/when they do not bring benefits, we anticipated that fish-induced diapause may be more common in Daphnia originating from water bodies inhabited by fish, as it would be unnecessary in those from fish-free locations.

\section{Materials and methods}

\section{Experimental media}

The experimental media were based on water from a city pond inhabited by fish. The pond water had been conditioned by aeration for at least 2 weeks prior to use. Such conditioning is sufficient to remove predator kairomones that originate from the field (Loose et al., 1993). Prior to use, the water was filtered through a $0.3-\mu \mathrm{m}$ filter and supplemented with green algae (Scenedesmus obliquus) as food for Daphnia, at a final concentration of $0.6 \mathrm{mg} \mathrm{C1^{-1 }}$. The so-called fish medium was prepared by diluting an extract of planktivorous fish faeces in this control medium to give a final concentration equivalent to the faeces excreted by one fish during $7 \mathrm{~h}$ in $10 \mathrm{l}$ of water. The extract of fish faeces was prepared a few months before the start of the experiment using a slight modification of the procedure described by Slusarczyk and Rygielska (2004). In brief, sixty small (10-15 cm) cyprinid fishes (crucian carp-Carassius carassius) were fed with $60 \mathrm{~g}$ of a frozen Daphnia shortly before the collection of faeces. The fish faeces were collected over $7 \mathrm{~h}$ and stored at $4^{\circ} \mathrm{C}$. They were then homogenized, filtered $(0.45 \mu \mathrm{m})$, diluted with water to the desired concentration (faeces of 1 fish per $1 \mathrm{ml}$ of extract), aliquoted into daily doses and frozen $\left(-20^{\circ} \mathrm{C}\right)$ for future use. This protocol for the preparation of cues on fish predation allowed us to control their quality and quantity along the experiment. Such a faecal extract remains inductive for at least 2 years when kept frozen at $-20^{\circ} \mathrm{C}$ (personal observation).

\section{Experimental animals}

The experimental clones of $D$. magna were collected from various locations as diapausing eggs. Exephippial females originated experimental clones that were maintained as laboratory cultures for 1-18 month prior to the experiment. Basic information concerning their native habitats is shown in Table 1. D. magna typically inhabits small and shallow freshwater ponds or lakes. Due to its relatively large body size, it is eagerly eaten by fish and typically occurs in fish-free locations, but occasionally it may be found in water bodies inhabited by fish. Here, we tested 35 clones of D. magna originating from various locations across 
Europe that are inhabited or uninhabited by fish (from Poland, Germany, Belgium and Spain, Table 1). All clones originating from Poland were obtained from fish-free city ponds. We are not aware of any natural reservoirs in Poland in which D. magna co-occurs with fish. The most variable and rich collection of D. magna clones came from water bodies in Belgium-some fish-free and others inhabited by fish. To enhance the chances of finding a positive reaction, we aimed to test three clones from each location, but this was not always possible. One clone originated from Grosser Binnensee, known for the positive diapause response to fish kairomones of its Daphnia, and this was used as a reference in this study to verify if the utilized kairomones remained inductive.

The method used for the reactivation of diapausing eggs and the experimental protocol were similar to those described in detail in our previous study (Slusarczyk et al., 2012). The ancestors of the experimental animals were kept under standardized favourable conditions for at least two generations to minimize potential effects of earlier environmental variability on the experimental results. Up to 10 sister females of a similar age were kept in 0.451 glass beakers containing water medium at a temperature of $20 \pm 0.1^{\circ} \mathrm{C}$ that was supplemented daily with a high concentration of algal food (Scenedesmus obliquus$1 \mathrm{mg} \mathrm{C} 1^{-1}$ ). The medium was exchanged every second day. Experimental females, randomly chosen from a group of synchronously-hatched offspring derived from the cohort of 10 sister females, were placed in experimental beakers within $24 \mathrm{~h}$ after birth.

\section{Experimental setup}

For the experiments, 10 randomly chosen neonates were placed in 0.41 lots of water medium (aerated and filtered pond water with algae) in 0.451 beakers. For each clone, three experimental replicates (water medium supplemented with fish cues) and three control replicates (water medium without fish cues) were set up in one of two experimental blocks. Because of capacity restrictions, the experiment was conducted in two blocks, both with the reference clone from the Grosser Binnensee. One of the three clones from each location was commonly tested in one block while two others in the other (with few exceptions). In the first block, the following clones were tested: 1P1, 3P2, 4P2, 8B4, 9B4, 11B5, 12B5, 13B6, 14B6, 16B7, 17B7, 19B8, 20B8, 22B9, 23B9, 25B10, 26B10, 28B11, 29B11, 30B12, 32S13, 35D14. The rest of experimental clones were tested in the second block: 2P1, 5P3, 6P3, 7P3, 10B4, 15B6, 18B7, 21B8, 24B9, 27B10, 31B12, 33S13, 34S13, 35D14. The experimental and control water media were exchanged in the beakers every second day (i.e. days $1,3,5 \ldots$ ), while algae and fish kairomones were supplied to the beakers every other day (i.e. days $2,4,6 \ldots$ ).

All beakers were held in a water bath at $22 \pm 0.1^{\circ} \mathrm{C}$ and lit by a fluorescent lamp with a 16L:8D photoperiod,

Table 1 Details about ponds/lakes of origin of experimental clones of D. magna

\begin{tabular}{llllcccc}
\hline Clone & Name & Fish & Stability & Area ha & Latitude & Longitude & Country \\
\hline 1P1, 2P1 & Pole Mokotowskie & - & $\mathrm{T}$ & 0.2 & $52^{\circ} 21^{\prime} 18^{\prime \prime} \mathrm{N}$ & $21^{\circ} 00^{\prime} 00^{\prime \prime} \mathrm{E}$ & Poland \\
3P2, 4P2 & No name & - & $\mathrm{T}$ & 0.3 & $52^{\circ} 25^{\prime} 33^{\prime \prime} \mathrm{N}$ & $21^{\circ} 01^{\prime} 21^{\prime \prime} \mathrm{E}$ & $\mathrm{Poland}$ \\
5P3, 6P3, 7P3 & Ksiązęca & - & $\mathrm{T}$ & 0.3 & $52^{\circ} 23^{\prime} 04^{\prime \prime} \mathrm{N}$ & $21^{\circ} 02^{\prime} 85^{\prime \prime} \mathrm{E}$ & $\mathrm{P}$ Poland \\
8B4, 9B4, 10B4 & Moorsel & - & $\mathrm{P}$ & 0.2 & $50^{\circ} 51^{\prime} 54^{\prime \prime} \mathrm{N}$ & $04^{\circ} 32^{\prime} 06^{\prime \prime} \mathrm{E}$ & $\mathrm{Belgium}$ \\
11B5, 12B5 & Citadelpark & - & $\mathrm{T} / \mathrm{P}$ & 0.01 & $51^{\circ} 03^{\prime} 62^{\prime \prime} \mathrm{N}$ & $03^{\circ} 72^{\prime} 17^{\prime \prime} \mathrm{E}$ & $\mathrm{Belgium}$ \\
13B6, 14B6, 15B6 & Tersaert 2 & - & $\mathrm{T} / \mathrm{P}$ & 0.03 & $50^{\circ} 49^{\prime} 18^{\prime \prime} \mathrm{N}$ & $04^{\circ} 36^{\prime} 04^{\prime \prime} \mathrm{E}$ & $\mathrm{Belgium}$ \\
16B7, 17B7, 18B7 & Zoete Waters 4 & + & $\mathrm{P}$ & 1.3 & $50^{\circ} 49^{\prime} 25^{\prime \prime} \mathrm{N}$ & $04^{\circ} 39^{\prime} 53^{\prime \prime} \mathrm{E}$ & $\mathrm{Belgium}$ \\
19B8, 20B8, 21B8 & Oude Meren 3 & + & $\mathrm{P}$ & 2.4 & $50^{\circ} 51^{\prime} 47^{\prime \prime} \mathrm{N}$ & $04^{\circ} 43^{\prime} 05^{\prime \prime} \mathrm{E}$ & $\mathrm{Belgium}$ \\
22B9, 23B9, 25B9 & Zoete Waters 3 & + & $\mathrm{P}$ & 2.7 & $50^{\circ} 49^{\prime} 23^{\prime \prime} \mathrm{N}$ & $04^{\circ} 39^{\prime} 39^{\prime \prime} \mathrm{E}$ & $\mathrm{Belgium}$ \\
25B10, 26B10, 27B10 & Oud-Heverlee Zuid & + & $\mathrm{P}$ & 9.8 & $50^{\circ} 50^{\prime} 22^{\prime \prime} \mathrm{N}$ & $04^{\circ} 39^{\prime} 18^{\prime \prime} \mathrm{E}$ & $\mathrm{Belgium}$ \\
28B11, 29B11 & Langerodevijver & + & $\mathrm{P}$ & 14.8 & $50^{\circ} 49^{\prime} 42^{\prime \prime} \mathrm{N}$ & $04^{\circ} 38^{\prime} 21^{\prime \prime} \mathrm{E}$ & $\mathrm{Belgium}$ \\
30B12, 31B12 & Oude Meren 2 & + & $\mathrm{P}$ & 3.0 & $50^{\circ} 51^{\prime} 48^{\prime \prime} \mathrm{N}$ & $04^{\circ} 43^{\prime} 17^{\prime \prime} \mathrm{E}$ & $\mathrm{Belgium}$ \\
32S13, 33S13, 34S13 & Albufera & + & $\mathrm{P}$ & 2320 & $39^{\circ} 33^{\prime} 56^{\prime \prime} \mathrm{N}$ & $0^{\circ} 35^{\prime} 49^{\prime \prime} \mathrm{W}$ & $\mathrm{Spain}$ \\
35D14 & Grosser Binnensee & + & $\mathrm{P}$ & 480 & $54^{\circ} 32^{\prime} 51^{\prime \prime} \mathrm{N}$ & $10^{\circ} 62^{\prime} 65^{\prime \prime} \mathrm{E}$ & $\mathrm{Germany}$ \\
\hline
\end{tabular}


simulating summer conditions. The number of ephippial females was recorded when the media were exchanged. At the same time, females bearing ephippia were removed from the beakers without replacement. This procedure permitted reliable assessment of the proportion of ephippial females in each treatment and prevented miscalculation due to possible multiple production of dormant eggs by a single female. When individuals were removed, the volume of medium in the beakers was reduced ( $40 \mathrm{ml}$ per female) to keep the animal densities constant throughout the course of the experiment. Newborn offspring were removed from the beakers when the medium was exchanged. Each experiment ran until all females released their 4th brood of eggs (about 4 weeks). As a measure of the diapause response, the cumulative proportion of females producing ephippia was scored for each beaker. Responsiveness to fish cues was assumed when clones formed significantly more ephippia in the medium with kairomones than in the control medium.

\section{Statistical analysis}

Responsiveness of the tested clones to fish cues was determined by pairwise comparisons of the proportion of ephippial females in the replicate beakers of medium with and without kairomones, using a nonparametric Mann-Whitney test for each clone separately. The reaction was considered significant at $P<0.05$, without corrections for multiple comparisons. The proportion of "responsive" clones, i.e. those forming ephippia in response to fish kairomones, obtained from fish-free habitats and from those inhabited by fish was compared in $2 \times 2$ contingency tables.

The Generalized Linear Mixed effect Model (GLMM) was used to test significance of the relation between the proportion of ephippial females and following effects: main fixed effects (a) the presence/absence of fish kairomones during the test, (b) the presence/absence of fish in the native water body of experimental animals, (c) experimental blocks, interaction fixed effects (a) with (b) and (a) with (c); two random components with random effects corresponding to (d) clonal identity of experimental animals, (e) the habitat of origin of experimental clones. The binomial family function with $\log -\log$ link function was used, model coefficients were estimated with the REML method. All computations were performed in $\mathrm{R}$ ver 3.0 statistical program ( $\mathrm{R}$ Core team, 2013) with lmer function from lme4 package ver. 0.999999-2 (Bates et al., 2013).

\section{Results}

Fish cues significantly increased the proportion of ephippial females in 15 of the 35 (i.e. 43\%) D. magna clones that were tested, according to pairwise comparisons with the Mann-Whitney test $(P<0.05)$ (Fig. 1). More specifically 7 of the 15 (47\%) tested clones that originated from fish-free locations formed significantly more ephippia when exposed to fish cues. In comparison, 8 of the $20(40 \%)$ tested clones originating from water bodies inhabited by fish were classified as responsive. The proportion of responsive clones did not differ significantly between fish and fish-free habitats, however. In summary, we found the responsive clones of D. magna in 10 of 14 (71\%) water bodies included in the analysis, Fig. 1.

GLMM analysis revealed that more experimental females formed ephippia in beakers containing fish kairomones $(52 \%)$ than in control beakers, not containing fish cues $(21 \%)$, Table 2. No significant difference in proportion of ephippial females was found between Daphnia originating from water bodies inhabited by fish (28\%) and Daphnia from fish-free locations (47\%). In Daphnia from fish-inhabited and fish-free locations kairomones increased the proportion of ephippial females from 14 to $42 \%$ and from 29 to $66 \%$, respectively, Fig. 2 . The interaction between the presence of fish kairomones and the origin of the tested clones (inhabited vs. uninhabited by fish) was not significant, Table 2.

The proportion of ephippial females appeared higher in the first experimental block (44\%) than in the second (24\%), Table 2. In the first and the second block, the addition of fish kairomones increased the proportion of ephippial females from 27 to $62 \%$ and from 12 to $35 \%$, respectively. The interaction between experimental block and the presence/absence of fish kairomones was not significant.

\section{Discussion}

The results of this study indicate that the diapause response to fish kairomones is common feature of 


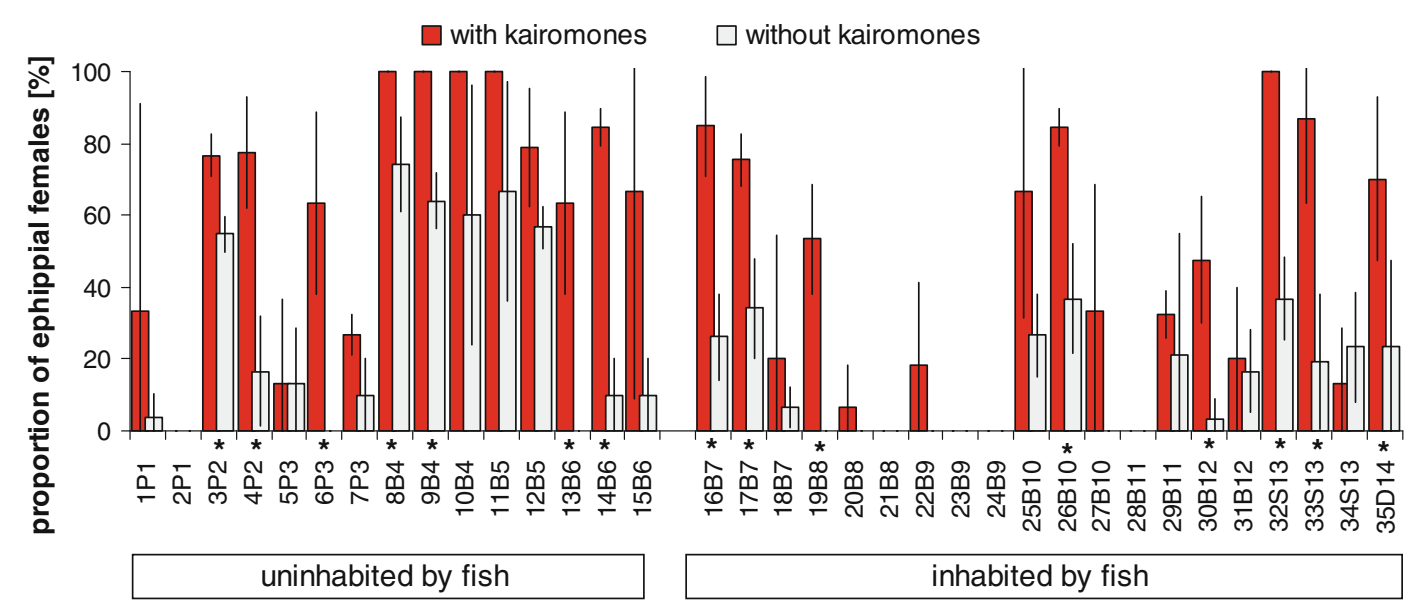

Fig. 1 Proportion (mean \pm SD) of ephippial females of Daphnia magna originating from European water bodies inhabited or uninhabited by fish, cultured in media with or without fish kairomones. Country of origin of the experimental clones is indicated by capital letters in the labels beneath the bars: $B$ Belgium, $D$ Germany, $P$ Poland, $S$ Spain. The numbers

Table 2 Results of a Generalized Linear Mixed effect Model testing the impact of analysed parameters on the proportion of ephippial females

\begin{tabular}{|c|c|c|c|c|}
\hline \multicolumn{2}{|l|}{ Fixed terms } & df & $t$ & $P$ \\
\hline \multicolumn{2}{|c|}{ Kairomone (presence/absence) } & 1 & 10.6 & 0.000 \\
\hline \multicolumn{2}{|c|}{ Fish presence/absence in native habitats } & 1 & -1.40 & 0.164 \\
\hline \multicolumn{2}{|c|}{ Experimental block } & 1 & -4.80 & 0.000 \\
\hline \multicolumn{2}{|c|}{$\begin{array}{l}\text { Kairomone: fish presence/absence in } \\
\text { native habitats }\end{array}$} & 1 & -0.63 & 0.526 \\
\hline \multicolumn{2}{|c|}{ Kairomone: experimental block } & 1 & 0.57 & 0.571 \\
\hline Random terms & $n$ levels & $\chi^{2}$ & & $P$ \\
\hline Clone identity & 35 & 12.4 & & 0.000 \\
\hline Habitat of origin & 14 & 82.4 & & 0.000 \\
\hline Observations & 216 & & & \\
\hline
\end{tabular}

Daphnia magna from European water bodies. We observed a significant diapause response in 15 of 35 (43\%) tested clones of D. magna originating from 10 of $14(71 \%)$ tested water bodies. Both responsive and non-responsive clones were frequently found in the same location, Fig. 1. Since our investigation was based upon, at most, three replicates of each clone, the statistical evaluation may have underestimated the real prevalence of this reaction. In this study, a compromise was made between the number of replicates and the number of tested clones. prior to the capital letters identify the tested clone; the numbers after them indicate the water body of origin of the clone. Stars below the bars denote significant differences between the experimental and control treatments for the given clone, determined by pairwise comparisons in individual MannWhitney tests $(P<0.05)$

Here, we examined the prevalence of the diapause response in a single species of Daphnia. Due to its large body size, D. magna seems to be at high risk of fish predation, and thus is likely to utilise this costly response to ensure survival in habitats containing fish. The findings of our previous study, which documented the occurrence of the diapause response in three species of Daphnia (D. magna, D. pulicaria and D. longispina) (Slusarczyk et al., 2012), together with the results of the present study, suggest that similar reaction may occur in many sites and species.

Since D. magna does not occur in deep lakes, the present study examined the prevalence of kairomoneinduced diapause in clones originating from shallow waters only: large brackish coastal lakes and small natural or man-made ponds. Results of our former study (Slusarczyk et al., 2005) indicate that the diapause response may be traded-off for other defence responses in potential prey e.g. diel vertical migration (DVM) in deep lakes. DVM is a common behaviour of Daphnia (Lampert, 1989; Sakwińska \& Dawidowicz, 2005), and is an effective escape unless safe dark refuge is absent or not accessible due to e.g. oxygen deficits (Sakwińska \& Dawidowicz, 2005; Gelinas et al., 2007).

In the present study, we had expected to document a higher proportion of both responsive clones and individuals in Daphnia originating from fish habitats, since natural selection should maintain this adaptation 


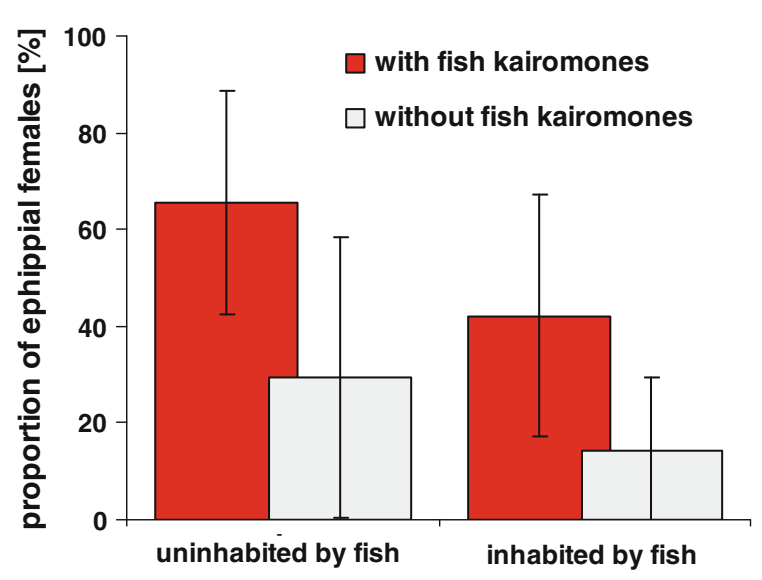

Fig. 2 Overall proportion (mean \pm SD) of ephippial females of Daphnia magna belonging to different clones originating from water bodies inhabited or uninhabited by fish

in water bodies inhabited by fish, but not necessarily in fish-free locations. However, neither higher proportion of responsive clones nor higher proportion of responsive individuals in Daphnia from fish habitats was evidenced. On the contrary, the proportion of ephippial females was insignificantly higher in Daphnia originating from fish-free locations than in those from habitats with fish. This can be most likely attributed to higher incidence of spontaneous diapause (formation of ephippia in the medium not containing fish cues) rather than to their more intense diapause response to fish cues. This is indicated by the insignificant interaction between the presence of fish kairomones and the origin of the tested clones. This corroborates our recent findings and may result from adaptations of Daphnia to the erratic nature of temporary habitats that lack fish (Slusarczyk \& Ochocka, in preparation). The fish-free environments inhabited by D. magna are typically small, seasonal or ephemeral pools that may disappear in an unpredictable manner (Pajunen \& Pajunen, 2007). In this type of habitat, resting forms may be produced spontaneously to protect against the unpredictable occurrence of catastrophic events (Cohen, 1966; Seger \& Brockmann, 1987; Altermatt \& Ebert, 2008). In contrast, fish typically inhabit permanent water bodies where changes of abiotic conditions are more predicable and signalled well in advance by some environmental cues (Hairston, 1987; Gliwicz, 2003). Yet what could explain similar proportion of Daphnia originating from habitats with and without fish that are responsive to fish kairomones? This refers not only to diapause induction as evidenced in the present study but also to many other inducible defences which may be maintained in fish-free habitats (Boersma et al., 1998). It might be that high dispersal capacity of Daphnia (Havel \& Shurin, 2004; Louette \& De Meester, 2005) may maintain existence of various defences against fish in fish-free locations, though they are adaptive only in habitats with fish.

We reported here high variability in incidence of ephippia formation between experimental beakers, which might have phenotypic, genetic, and stochastic components. The first were evidenced by the significant effect of fish kairomones on ephippia formation. The second was indicated by substantial differences in diapause response to fish kairomones between clones from same or different locations. The third would result from all kinds of uncontrolled factors in experimental studies including developmental instability of clonal animals (Babbitt, 2008). High variation in expression of other defence responses (behavioural, morphological or life history ones) of various clones of D. magna originating from water bodies inhabited or uninhabited by fish was earlier reported by De Meester (1996) and Boersma et al. (1998).

If the diapause induction in response to predator kairomones is common, as is indicated by the results of this study, why has it not been more widely reported so far? Most likely specific conditions required for his response have not been applied in previous studies. In their influential paper, Loose et al. (1993) reported that Daphnia behavioural responses to fish-treated water were similar irrespective of whether the fish were or were not fed with Daphnia. Since then, in many, if not in most studies on chemical induction of defence responses, fish food was not controlled for. Here, we fed fish with Daphnia, as we had previously found it to be an essential prerequisite for the accumulation of effective stimuli able to induce ephippia formation in conspecific prey (Slusarczyk, 1999). There was also a debate about the origin of fish kairomones. Some researchers assumed that they are directly released by fish through skin, gills or hindgut (Loose et al., 1993), some other claimed that the kairomones are formed by bacteria associated with fish skin mucus (Ringelberg \& Van Gool, 1998; Beklioglu et al., 2006). We used here faeces of fish that were fed with Daphnia as we found it to be a more effective source of chemical signals inducing diapause in Daphnia than water inhabited by fish (Slusarczyk \& Rygielska, 2004). The 
greatest benefit of our method is that the concentrated extract of fish faeces can be easily collected, processed and preserved in high quantities. This assures application of similar quantity and quality of the inductive cue throughout the entire experiment or a few experiments if needed. According to our findings frozen extract of fish faeces retains its diapause inductive effect for at least 2 years (personal observation). Higher proportion of ephippial females in the first than in the second experimental block in our study might falsely suggest the decrease of frozen fish kairomones activity with time. We reject this claim basing on the fact that there was no interaction between fish kairomones treatment and experimental block. As in the first block more ephippia were formed in both-control and experimental-treatments, the observed between-block difference was due to factors other than kairomone activity.

According to our findings, diapause response to predation cues may be disfavoured by high food concentration and temperature or the presence of antipredatory refuge (Slusarczyk, 2004). In natural environments, these factors may enhance the chances of survival in an active form during periods of predation pressure and make diapause a less rewarding option. Therefore, experimental verification of the existence of the diapause response to predation cues should be done under specific conditions that favour this response in nature, i.e. low food concentration, low temperature, and environmental conditions that unable prey to use alternative defence responses.

While most examples of predatory avoidance diapause come from freshwater habitats, there is no ultimate reason why it should not be found also in other locations.

Acknowledgments We are grateful to Sarah Rousseau and Luc De Meester from Katholieke Universiteit Leuven for providing us with a rich collection D. magna clones from Belgium. We thank Maria Sahuquillo and Maria Rosa Miracle and from Valencia University for providing us with ephippia of D. magna from the Albufera lake in Spain. We would also like to thank Ania Bednarska, Barbara Pietrzak and two anonymous reviewers for helpful and constructive comments on the manuscript. The study was supported by the grant money form Polish Ministry of Science and Higher Education (NN304138940).

Open Access This article is distributed under the terms of the Creative Commons Attribution License which permits any use, distribution, and reproduction in any medium, provided the original author(s) and the source are credited.

\section{References}

Altermatt, F. \& D. Ebert, 2008. The influence of pool volume and summer desiccation on the production of the resting and dispersal stage in a Daphnia metapopulation. Oecologia 157: 441-452.

Babbitt, G. A., 2008. How accurate is the phenotype? - an analysis of developmental noise in a cotton aphid clone. BMC Developmental Biology 8: 9.

Bates, D., M. Maechler \& B. Bolker, 2013. lme4: Linear mixedeffects models using S4 classes. R package version 0.999999-2. http://CRAN.R-project.org/package=lme4.

Beklioglu, M., M. Telli \& A. G. Gozen, 2006. Fish and mucusdwelling bacteria interact to produce a kairomone that induces diel vertical migration in Daphnia. Freshwater Biology 51: 2200-2206.

Boersma, M., P. Spaak \& L. De Meester, 1998. Predator-mediated plasticity in morphology, life history, and behavior of Daphnia: the uncoupling of responses. The American Naturalist 152: 237-248.

Brendonck, L. \& L. De Meester, 2003. Egg banks in freshwater zooplankton: evolutionary and ecological archives in the sediment. Hydrobiologia 491: 65-84.

Cohen, D., 1966. Optimizing reproduction in a randomly varying environment. Journal of Theoretical Biology 12: 119-129.

De Meester, L., 1996. Evolutionary potential and local genetic differentiation in a phenotypically plastic trait of a cyclical parthenogen, Daphnia magna. Evolution 50: 1293-1298.

Gelinas, M., B. Pinel-Alloul \& M. Slusarczyk, 2007. Alternative antipredator responses of two coexisting Daphnia species to negative size selection by YOY perch. Journal of Plankton Research 29: 775-789.

Gliwicz, Z. M., 2003. Between Hazards of Starvation and Risk of Predation: The Ecology of Offshore Animals. International Ecology Institute, Oldendorf/Luhe: 379 pp.

Gyllström, M. \& L. A. Hansson, 2004. Dormancy in freshwater zooplankton: induction, termination and the importance of benthic-pelagic coupling. Aquatic Sciences - Research Across Boundaries 66: 274-295.

Hairston, N. G. J., 1987. Diapause as a predator-avoidance adaptation. In Kerfoot, W. C. \& A. Sih (eds), Predation: Direct and Indirect Impacts on Aquatic Communities. Univ. Press New England, Hanover, London: 281-290.

Hairston, N. G. J. \& E. J. Olds, 1984. Population differences in the timing of diapause: adaptation in a spatially heterogeneous environment. Oecologia 61: 42-48.

Havel, J. E. \& J. B. Shurin, 2004. Mechanisms, effects, and scales of dispersal in freshwater zooplankton. Limnology and Oceanography 49: 1229-1238.

Kroon, A., R. L. Veenendaal, J. Bruin, M. Egas \& M. W. Sabelis, 2008. Sleeping with the enemy-predator-induced diapause in a mite. Naturwissenschaften 95: 1195-1198.

Lampert, W., 1989. The adaptative significance of diel vertical migration of zooplankton. Functional Ecology 3: 21-27.

Loose, C. J., E. Von Elert \& P. Dawidowicz, 1993. Chemicallyinduced diel vertical migration in Daphnia: a new bioassay for kairomones exuded by fish. Archiv fuer Hydrobiologie 126: 329-337. 
Louette, G. \& L. De Meester, 2005. High dispersal capacity of Cladoceran zooplankton in newly founded communities. Ecology 86: 353-359.

Marcus, N. H., 1984. Recruitment of copepod nauplii into the plankton: importance of diapause eggs and benthic processes. Marine Ecology Progress Series 15: 47-54.

Mellors, W. K., 1975. Selective predation of ephippial Daphnia and the resistance of ephippial eggs to digestion. Ecology 56: 974-980.

Pajunen, V. I. \& I. Pajunen, 2007. Habitat characteristics contributing to local occupancy and habitat use in rock pool Daphnia metapopulations. Hydrobiologia 592: 291-302.

Pijanowska, J. \& G. Stolpe, 1996. Summer diapause in Daphnia as a reaction to the presence of fish. Journal of Plankton Research 18: 1407-1412.

R Core Team, 2013. R: A language and environment for statistical computing. R Foundation for Statistical Computing, Vienna, Austria. URL http://www.R-project.org/.

Ringelberg, J. \& E. VanGool, 1998. Do bacteria, not fish, produce "fish kairomone"? Journal of Plankton Research 20: 1847-1852.

Sakwińska, O. \& P. Dawidowicz, 2005. Life history strategy and depth selection behavior as alternative antipredator defenses among natural Daphnia hyalina populations. Limnology and Oceanography 50: 1284-1289.

Seger, J. \& H. J. Brockmann, 1987. What is bet-hedging? Oxford Survey of Evolutionary Biology 4: 182-211.

Slusarczyk, M., 1999. Predator induced diapause in Daphnia magna may require two chemical cues. Oecologia 119: 159-165.

Slusarczyk, M., 2004. Environmental plasticity of fish avoidance diapause response in Daphnia magna. Journal of Limnology 63: 70-74.

Slusarczyk, M. \& E. Rygielska, 2004. Fish faeces as the primary source of chemical cues inducing fish avoidance diapause in Daphnia magna. Hydrobiologia 526: 231-234.

Slusarczyk, M., P. Dawidowicz \& E. Rygielska, 2005. Hide, rest or die: a light-mediated diapause response in Daphnia magna to the threat of fish predation. Freshwater Biology 50: 141-146.

Slusarczyk, M., A. Ochocka \& D. Cichocka, 2012. The prevalence of diapause response to risk of size-selective predation in small- and large-bodied prey species. Aquatic Ecology 46: 1-8. 